\title{
Métodos de controle de plantas daninhas em sistemas orgânicos: breve revisão
}

\author{
Methods of weed control in organic systems: a short review \\ Neumarcio Vilanova Costa ${ }^{1 *}$, Andreia Cristina Peres Rodrigues-Costa ${ }^{2}$, \\ Érica Marusa Pergo Coelho ${ }^{2}$, Sílvio Dougla Ferreira ${ }^{3}$, Jaqueline de Araujo Barbosa ${ }^{3}$
}

\begin{abstract}
Resumo - O manejo das plantas daninhas em sistemas orgânicos de produção agrícola representa um grande desafio aos produtores. Para o enfretamento deste desafio torna-se necessário a exploração de práticas de manejo sustentáveis e o desenvolvimento de novas tecnologias. Ressalta-se que existe alternativas tecnológicas ou biológicas que podem ser utilizadas no manejo das plantas daninhas em sistemas orgânicos, e serem empregadas em grandes áreas. Estratégias culturais, biológicos, mecânicos e físicos de manejo podem ser eficientes no controle das plantas daninhas, bem como reduzir o uso de controle químico na agricultura convencional. Desta forma, esta revisão de literatura teve como objetivo o de apresentar métodos alternativos de controle de plantas daninhas e o potencial uso em áreas orgânicas de produção agrícola. Os métodos de controle das plantas daninhas em áreas orgânicas devem abordar sempre estratégias integradas e de forma sustentável.
\end{abstract}

Palavras-chave: agroecossistemas, controle alternativo, plantas espontâneas

\begin{abstract}
Weed management in organic systems of agricultural production is a major challenge to agricultural farmers. To solve this challenge, it is necessary to explore sustainable management practices and the development of new technologies. It should be emphasized that there are technological or biological alternatives that can be used in weed management in organic systems, and are used in large areas. Cultural, biological, mechanical and physical management strategies can be effective in controlling weeds, as well as reducing the use of chemical control in conventional agriculture. Thus, this literature review aimed to present some alternative methods of weed control and potential use in organic areas of agricultural production. Weed control methods in organic areas should always use integrated and sustainable strategies.
\end{abstract}

Keywords: agroecosystems, alternative control, spontaneous plants

Received: January 27, 2017. Accepted: December 25, 2017.

${ }^{1}$ Universidade Estadual do Oeste do Paraná - UNIOESTE, Rua Pernambuco, nº 1777, CP 91, CEP 85960-00,

Marechal Cândido Rondon, PR, Brasil. E-mail: neumarciovc@hotmail.com

${ }^{2}$ Universidade Estadual de Maringá - UEM, Umuarama, PR, Brasil. E-mail: andreiacpr@hotmail.com; profericapergo@gmail.com

${ }^{3}$ Programa de Pós-graduação em Agronomia, Universidade Estadual do Oeste do Paraná - UNIOESTE, Marechal Cândido Rondon, PR, Brasil. E-mail: agrosilvio@outlook.com; jaquelineabarbosa@hotmail.com 


\section{Introdução}

O controle das plantas daninhas destaca-se dentre as principais problemáticas enfrentadas pelos produtores de alimentos no mundo. A interferência da comunidade infestante das plantas daninhas pode reduzir o potencial produtivo em $96,9 \%$ da cultura do arroz (Silva e Durigan, 2009), em 35,8\% do feijão (Borchartt et al., 2011), em 46,0\% da soja (Nepomuceno et al., 2007), em $65,0 \%$ do milho (Gantoli et al., 2013) e 31,0\% do trigo (Agostinetto et al., 2008).

Para evitar as perdas devido a matocompetição em áreas agrícolas são necessários o emprego de medidas de controle da comunidade infestante. Ressalta-se que em áreas de produção com base na agricultura agroecológica a tomada de decisão para a realização do controle das plantas daninhas deve considerar os mesmos critérios utilizados na agricultura convencional, com exceção ao uso de herbicidas.

A adoção de novas formas de manejo das plantas daninhas e da integração de métodos culturais, biológicos, mecânicos e físicos de controle são importantes para substituir ou até mesmo reduzir o uso de controle químico na agricultura convencional, uma vez que o uso indevido de herbicidas causa muitos problemas ao meio ambiente e ao homem (Galon et al., 2016). Entretanto, a definição do método de controle das plantas daninhas pode ser dependente do tipo de comunidade infestante presente, solo, da tolerância da variedade a matocompetição, aspectos econômicos (custo de controle e valor da cultura), disponibilidade de mão de obra e de equipamentos.

Portanto, torna-se fundamental o aprimoramento de práticas culturais como o uso de plantas de cobertura com elevada produção de palhada e potencial alelopático, uma vez que, os efeitos físicos e químicos da cobertura morta podem interferir na germinação e na taxa de sobrevivência das plântulas de espécies de plantas daninhas (Monquero et al., 2009). Da mesma maneira, pode se explorar compostos naturais produzidos por plantas, fungos, bactérias, vírus e insetos como bioherbicidas seletivos e eficientes (Hallett, 2005; Dias e Dias, 2007; Ash, 2010).

Com relação ao controle mecânico, o desenvolvimento de cultivadores ou capinadores mecânicos automatizados aumenta o rendimento operacional e a eficiência do manejo das plantas daninhas (Fennimore et al., 2016), correspondendo a uma alternativa à baixa disponibilidade de mão de obra no campo, que praticamente inviabiliza o controle manual principalmente em grandes áreas, além de ser oneroso. Deste modo, para a automação do controle mecânico das plantas daninhas pode-se utilizar no trator câmeras de vídeo com sistema de detecção em tempo real da linha da cultura ou de mapeamento da infestação por GPS (Pérez-Ruiz et al., 2012). Estes sistemas auxiliam no controle das planas daninhas na entrelinha e na linha sem causar danos severos nas culturas.

De modo semelhante, os sistemas de automação pode ser adaptados a equipamentos de controle térmico por meio de fogo (gás propano) e de eletricidade para ampliação dos métodos de controle das plantas daninhas não somente para culturas orgânicas como também para as convencionais (Mizuno, 1999; Melander et al., 2005; Cisneros e Zandstra, 2008; Brighenti e Brighenti, 2009).

O sucesso do controle das plantas daninhas em qualquer sistema agrícola pode ser dependente dos métodos e das estratégias de manejo utilizados. Portanto, o desenvolvimento de estratégias culturais, biológicos, mecânicos e físicos são fundamentais para elaboração de programas de manejo integrado das plantas daninhas, principalmente em sistemas agroecológicos (Rask e Kristoffersen, 2007; Pérez-Ruiz et al., 2012; Knezevic et al., 2014). Além de que, a integração de métodos de controle pode evitar a seleção de biótipos tolerantes/adaptados a determinado método, como já ocorre nos agrossistemas que utilizam variedades transgênicas resistentes a herbicidas. 
Desta forma, realizou-se uma revisão de alguns métodos alternativos de controle de plantas daninhas e o potencial uso em áreas orgânicas de produção agrícola.

\section{Supressão de plantas daninhas pela cobertura morta}

O sistema de Plantio Direto e o de Integração Lavoura Pecuária apresentam excelente contribuição no controle das plantas daninhas em sistemas orgânicos devido a manutenção de palhada sobre o solo. Entretanto, o manejo da palhada antes da semeadura da cultura e da possibilidade de rebrotas das plantas de cobertura, ainda são gargalos que devem ser melhorados.

A cobertura do solo pelos restos culturais, representa excelente alternativa, uma vez que quando bem formada e distribuída uniformemente sobre a superfície do solo, age física e mecanicamente sobre o banco de sementes de plantas daninhas, diminuindo a taxa de germinação, além de contribuir na melhoria das características físicas, químicas e biológicas do solo e na manutenção da temperatura e da umidade (Pitelli e Durigan, 2001; Noce et al., 2008). Plantas de cobertura podem ainda apresentar efeito alelopático, que consiste no efeito inibitório ou estimulativo de uma planta sobre outras espécies, resultado da liberação de substâncias químicas no ambiente, contribuindo também na redução da população infestante (Scholberg et al., 2006).

A composição específica e as densidades populacionais das comunidades infestantes podem ser influenciadas pelos sistemas de produção de cobertura morta, como exemplo, verificou-se que quantidades de palha de sorgo de 1,5 e 1,1 t haforam suficientes para reduzir as infestações de Sida rhombifolia e Brachiaria plantaginea em 50\%, comparativamente à testemunha sem cobertura morta na superfície, além disso, palha de sorgo ou milheto na quantidade de $4 \mathrm{tha}^{-1}$ na superfície do solo, foram suficientes para reduzir 91,96 e 59\% da população total de S. rhombifolia,
B. plantaginea, e Bidens pilosa, respectivamente (Trezzi e Vidal, 2004).

Em outro estudo, as quantidade de palhadas de 3,0 a 5,5 tha-1 dos adubos verdes, sorgo (Sorghum bicolor), milheto (Pennisetum americanum), capim-pé-de-galinha (Eleusine coracana) e braquiária (Brachiaria brizantha), foram capazes de inibir, além da emergência, o crescimento e o desenvolvimento de Bidens pilosa, Amaranthus spp., Commelina benghalensis, Leucas martinicensis e gramíneas (Correia et al., 2006). Do mesmo modo, as palhadas da mucuna-preta (Mucuna aterrinum - 7,5 $\mathrm{t} \mathrm{ha}^{-1}$ ) e da crotalária (Crotalaria juncea - 9,3 $\mathrm{t} \mathrm{ha}^{-1}$ ) proporcionaram reduções de 84,6 e 70,5\% da população das plantas daninhas, respectivamente, em sistemas orgânicos de produção de milho-verde (Queiroz et al., 2010).

O sombreamento do solo proporcionado pelas palhadas dos adubos verdes possibilita às plantas da cultura de interesse se desenvolverem sob efeito de menor competição inicial com as plantas daninhas tanto em sistemas orgânicos quanto convencional (Melo et al., 2007). Outro aspecto importante que contribui no manejo das plantas daninhas, refere-se a utilização de cultivares competitivas e de crescimento rápido para o abafamento da região da entrelinha e impedir a germinação do banco de sementes.

Os efeitos físicos da palhada sobre o processo germinativo podem ser exemplificados com a redução da germinação de sementes fotoblásticas positivas, das sementes que requerem determinado comprimento de onda, das sementes que necessitam de grande amplitude de variação térmica para inibir o processo germinativo e de sementes com pequena quantidade de reservas nos diásporos (Monquero et al., 2009; Yamauti et al., 2011).

As Poaceae, Digitaria bicornis e Digitaria horizontalis necessitam de luz para a germinação, diferentemente da Digitaria ciliaris e a Digitaria insularis (Mondo et al., 2010). As espécies da família das Compositae, Acanthospermum hispidum, Ayeratum conysoides, Bidens pilosa, Emilia sonchifolia, Erigeron bonariensis, Eupatorium pauciflorum, Galinsoga 
parviflora e Xanthium strumariu; as Cruciferae, Lepidium ruderale e L. virginicum; as Euphorbioceae, Euphorbia brasiliensis, E. heterophylla, E. pilulifera e Phyllantus corcovadensis; a Portulacaceae, Portulaca oleracea, são fotoblásticas positivas, enquanto que as sementes de Porophyllum ruderale(Compositae), Panicum maximum (Poaceae), Ipomoea indica (Convolvulaceae), Malvastrum coromandelianum e Sida cordifolia (Malvaceae) são indiferente à luz para a germinação (Klein e Felippe, 1991).

A presença palhada sobre o solo também pode contribuir na redução da germinação de espécies que possuem sementes com grande quantidade de reservas e que não necessitam de luz para germinar, a exemplo do capim camalote (Rottboellia exaltata) (Monquero et al., 2012). Contudo, nem sempre a presença de palha sobre o solo inibe totalmente a emergência de sementes que precisam de luz germinar. A Euphorbia heterophylla, espécie fotoblástica positiva ou preferencial (Klein e Felippe, 1991) teve 33,7\% de redução da emergência das sementes sob $8 \mathrm{tha}^{-1} \mathrm{de}$ palha de cana-de-açucar, mas não houve inibição (Yamauti et al., 2011). Estes resultados evidenciam o potencial adaptativo das espécies de plantas daninhas a diversos sistemas agrícolas.

A utilização de plantas de cobertura ou adubação verde pode trazer vantagens ao produtor que incentive a sua adoção na propriedade de forma econômica. Em algumas regiões agrícolas, permite a utilização de plantas de coberturas como culturas comerciais, como, por exemplo, trigo, aveia branca e aveia-preta, dos quais também poderá se obter receita, além do efeito supressor na germinação e emergência de espécies resistentes (Conyza bonariensis) (Lamego et al., 2013; Mahmood et al., 2015).

Portanto, a utilização de plantas de cobertura em programas de rotação de culturas com integração a outros métodos de manejo pode evitar a seleção de espécies de difícil controle em áreas de sistemas tradicionais de produção, áreas em conversão ao sistema agroecológico ou já consolidadamente orgânicos.

\section{Potencial alelopático de extratos vegetais sobre plantas daninhas}

A cobertura morta pode ter influência alelopática sobre as plantas daninhas, entretanto, os efeitos químicos depende diretamente da qualidade e da quantidade do material vegetal depositado na superfície, do tipo de solo, da população microbiana, das condições climáticas e da composição de espécies da comunidade de plantas daninhas de forma específica (Monquero et al., 2009).

A alelopatia pode ser definida como o efeito inibitório ou benéfico, direto ou indireto, de uma planta sobre outra, via produção de compostos químicos que são liberados no ambiente (Souza et al., 2006). Os compostos alopáticos são oriundos do metabolismo secundário da planta e são liberados no ambiente pela decomposição da matéria orgânica, exudação radicular ou por substâncias voláteis no ar.

A inibição na germinação ou no crescimento de plantas daninhas por meio de substâncias alelopáticas apresenta-se como alternativa no manejo integrado de plantas daninhas, uma vez que, o uso potencial do extrato como um agente químico natural, como também pela presença de novos compostos químicas presentes nos extratos, as quais podem potencialmente ser utilizados como bioherbicidas (Pires et al., 2001; Galon et al., 2016).

Ensaios realizados com capim-marmelada e seu componente metabólico o ácido aconítico, demonstraram seus efeitos sobre a inibição da germinação de plantas daninhas na cultura de soja, dentre elas a Commelina benghalensis, Euphorbia heterophylla e Ipomoea grandifolia, apresentando, portanto, efeitos de controle de infestações dessas plantas daninhas (Voll et al., 2004, 2005).

As substâncias dos extratos aquosos de sorgo (Sorghum spp.), planta largamente utilizada como cobertura vegetal, causaram efeitos negativos sobre plantas cultivadas, imediatamente após 
a retirada da cobertura (Trezzi e Vidal, 2004). Similarmente, o extrato aquoso de metanol de Brachiaria brizantha promoveram inibição do crescimento de raízes e mudas azevém (Lolium multiflorum) (Kato-Noguchi et al., 2014). Rickli et al. (2011), verificaram que o extrato de Nim sobre a germinação de Bidens pilosa, diminuiu a porcentagem de germinação de acordo com o aumento da concentração do extrato, sendo significativo nas concentrações de 80 e $100 \%$, e proporcionaram 7 e $12 \%$ de germinação respectivamente. O que demonstra um potencial alelopático negativo sobre essa espécie.

A aplicação do extrato aquoso de folhas frescas de girassol a $40 \%$, inibiu totalmente a germinação de sementes e desenvolvimento inicial de plântulas de picão preto (Bidens pilosa L.), indicando que a palhada de girassol poderia servir como um herbicida natural (Corsato et al., 2010). Do mesmo modo, foi constatada a ação herbicida dos extratos metanólicos de caule e raiz de Caryocar brasiliense, popularmente conhecido como pequi, em ensaios de germinação de sementes de Panicum maximum (Rezende et al., 2011).

Dos extratos vegetais com potencial alelopático que resultaram na produção de herbicidas comerciais, destaca-se o Mesotriona. Este herbicida pertencente a família das benzoilciclohexanodiona, que são derivadas quimicamente da fitotoxina natural leptospermona, obtida da planta Callistemon citrinus (Mitchell et al., 2001). O mesotriona é um herbicida que desenvolvido para o controle seletivo pré e pós-emergência de uma ampla gama de plantas daninhas de folhas largas e gramíneas em milho (Zea mays). O herbicida atua por inibição competitiva da enzima 4-hidroxifenilpiruvato dioxigenase (HPPD), um componente da via bioquímica que converte tirosina em plastoquinona e $\alpha$-tocoferol.

$\mathrm{Na}$ literatura, podem ser encontrados alguns exemplos de produtos comerciais que contêm produtos naturais utilizados no controle das plantas daninhas na agricultura orgânica (Dayan et al. 2009), a base de: glúten de milho, óleo de soja, ácido pelargónico, ácidos graxos de cadeia curta, óleo de petróleo parafínico, óleo de cravo, lauril sulfato de sódio, ácido acético, lecitina, ácido cítrico, óleo mineral, óleo de gergelim, extratos de mandioca, óleo de alho, óleo de pinho, vinagre, óleo de canela, óleo de citrus, óleo de capim-limão e outros; entretanto, ao contrário dos herbicidas sintéticos, os herbicidas naturais têm pouca ou nenhuma seletividade e devem ser aplicados em quantidades relativamente grandes, além disso, existem poucas informações referentes ao uso e o impacto ambiental dos produtos naturais na agricultura orgânica.

Na Tabela 1, estão descritos alguns exemplos de plantas que apresentam potencial alelopático e que podem ser fontes de compostos para novos herbicidas e explorados no manejo integrado de plantas daninhas.

Ressalta-se que os resultados experimentais obtidos em laboratório ou em casa de vegetação são difíceis de serem extrapolados em condições de campo, pois os aleloquímicos oriundos do metabolismo secundário das plantas que são liberados no ambiente e sofrem transformações pela ação de fatores bióticos (microflora do solo e exudados das raízes de outros competidores) e abióticos (variação da temperatura e umidade do solo) de forma a ativa-los ou inativa-los como agentes de controle biológico, além de que, falta informações sobre o modo de ação, se os aleloquímicos agem de isoladamente ou se são dependente de outros compostos (antagonismo e sinergismo) e de sua persistência no solo (Ferreira e Aquila, 2000; Reigosa et al., 2013; Dayan et al., 2009; Duke, 2015).

Entretanto na prática, a introdução de adubos verdes com elevado potencial alelopático nos programas de rotação de culturas pode aumentar a efetividade no controle das plantas daninhas a campo. Outra alternativa discutida por Santos et al. 
Tabela 1. Exemplos de plantas com potencial alelopático (planta doadora e planta receptora).

\begin{tabular}{|c|c|c|c|}
\hline Planta Doadora & Planta receptora & $\begin{array}{c}\text { Efeito causado sobre as espécies } \\
\text { receptoras }\end{array}$ & Referência \\
\hline Helianthus annus & Bidens pilosa & $\begin{array}{l}\text { Porcentagem de germinação } \\
\text { totalmente inibida quando aplicado o } \\
\text { extrato aquoso a } 40 \% \text {. }\end{array}$ & Corsato et al. (2010) \\
\hline $\begin{array}{c}\text { Leucaena } \\
\text { leucocephala }\end{array}$ & $\begin{array}{c}\text { Bidens pilosa } \mathrm{e} \\
\text { Amaranthus hybridus }\end{array}$ & $\begin{array}{l}\text { As concentrações de } 50 \text { e } 100 \% \text { do } \\
\text { extrato induziram a uma redução } \\
\text { no crescimento das plantas e à } \\
\text { deformação no limbo foliar. }\end{array}$ & Pires et al. (2001) \\
\hline Camelina sativa & Bidens pilosa & $\begin{array}{l}\text { Houve alteração linear dos parâmetros } \\
\text { tempo e velocidade média de } \\
\text { germinação conforme aumento da } \\
\text { concentração do extrato. }\end{array}$ & Silva et al. (2011a) \\
\hline $\begin{array}{c}\text { Leucaena } \\
\text { leucocephala }\end{array}$ & Bidens pilosa & $\begin{array}{l}\text { O extrato aquoso da parte aérea da } \\
\text { leucena reduziu a taxa de germinação. }\end{array}$ & Peron e Bonini (2012) \\
\hline $\begin{array}{l}\text { Canavalia } \\
\text { ensiformis e } \\
\text { Pennisetum } \\
\text { glaucum }\end{array}$ & Brachiaria brizantha & $\begin{array}{l}\text { Diminuição do comprimento médio } \\
\text { de raiz, massa fresca de raiz, massa } \\
\text { seca de raiz, comprimento médio de } \\
\text { parte aérea, massa fresca de parte } \\
\text { aérea e massa seca de parte aérea. }\end{array}$ & Carvalho et al. (2016) \\
\hline $\begin{array}{l}\text { Avena sativa e } \\
\text { Avena strigosa }\end{array}$ & $\begin{array}{l}\text { Euphorbia heterophylla } \mathrm{e} \\
\text { Lolium multiflorum }\end{array}$ & $\begin{array}{c}\text { Extratos da parte aérea provocaram } \\
\text { reduções na germinação e no } \\
\text { crescimento da radícula e do } \\
\text { hipocótilo. }\end{array}$ & Hagemann et al. (2010) \\
\hline $\begin{array}{c}\text { Brachiaria } \\
\text { plantaginea }\end{array}$ & $\begin{array}{l}\text { Commelina benghalensis, } \\
\text { Euphorbia heterophylla } \mathrm{e} \\
\text { Ipomoea grandifolia }\end{array}$ & Redução na germinação. & Voll et al. (2004 e 2005) \\
\hline $\begin{array}{c}\text { Brachiaria } \\
\text { brizantha }\end{array}$ & Lolium multiflorum & $\begin{array}{l}\text { Extrato aquoso de metanol, inibiu o } \\
\text { crescimento de raízes e mudas. }\end{array}$ & Kato-Noguchi, et al. (2014) \\
\hline Sorghum bicolor & Várias espécies & $\begin{array}{l}\text { Produz composto denominado } \\
\text { de sorgoleone, capaz de inibir a } \\
\text { fotossíntese. }\end{array}$ & Santos et al. (2012) \\
\hline
\end{tabular}

(2012), Worthington e Reberg-Horton (2013) e Bajwa et al. (2015) seria a melhoria da habilidade competitiva e do potencial alelopático das culturas comerciais por meio da engenharia genética.

\section{Agentes biológicos com potencial para o controle de plantas daninhas}

O uso de organismos vivos como estratégia de controle para as plantas daninhas demonstra interesse por apresentar reduzido impacto ambiental, custo acessível, e resultados semelhantes aos obtidos com herbicidas no sistema convencional. Entretanto, organismos vivos exigem cuidados redobrados, sejam relacionados às condições de cultivo, de conservação, de estocagem, sendo que, cada organismo possui condições ótimas de desenvolvimento, que iram proporcionar maior viabilidade e produção (Machado et al., 2013; Moraes et al., 2014). O uso de fungos, bactérias, vírus e insetos para o controle de plantas daninhas se enquadra dentro da perspectiva de controle biológico, e usualmente está sendo conhecida como bioherbicida (Bittencourt e Franzener, 2013; Galon et al., 2016). Este método alternativo de controle tem demonstrado resultados promissores em testes de laboratório. 
Resultados encontrados na literatura apontam que fungos podem ser potenciais para a supressão de plantas daninhas, pois são hospedeiros naturais e necessitam das mesmas para sobrevivência, consequentemente, podem ser utilizados em estratégias de controle, contudo, estudos à campo e avaliações quanto a seletividade, necessitam ser melhor exploradas.

Esporos do fungo Plectosporium alismatis $\left(2 \times 10^{6}\right.$ esporos $\left.\mathrm{ml}^{-1}\right)$ são capazes de induzir em média de $86,1 \%$ de queima foliar em plantas de Sagittaria montevidensis, induzindo sintomas entre três a quatro dias após a inoculação, com queima das folhas, interrupção do crescimento e morte da folhagem, inclusive de folhas novas que surgiam em até dez dias após a aplicação (Lima et al., 2010).

De forma similar, a formulação granular produzida a partir de esporos do fungo Fusarium oxysporum possui potencial para o controle da planta daninha Orobanche ramosa, sendo que, segundo resultados obtidos por Müller-Stover et al. (2009), a formulação resultou em redução da massa seca da planta daninha em mais de 90\%.

Espécies de fungos avaliadas como potenciais para o controle de plantas daninhas podem induzir sintomas e ocasionar danos em culturas de interesse, portanto, avaliar a seletividade do patógeno se torna indispensável. $\mathrm{O}$ fungo Golovinomyces cichoracearum, por exemplo, agente casual do oídio, apesar de causar danos em culturas economicamente importantes, possui potencial para limitar a expansão da planta daninha Tragopogon dubius Scop. em áreas agrícolas, induzindo sintomas na planta daninha cinco dias após a inoculação (Hong et al., 2016). Em outro estudo, Kurose et al. (2015), inocularam o fungo Mycosphaerella polygoni-cuspidati na planta daninha Fallopia japonica, e observaram que as plantas mantidas em temperaturas de 20 a $25^{\circ} \mathrm{C}$, demonstraram sintomas expressivos, enquanto que as plantas daninhas mantidas a $10^{\circ} \mathrm{C}$, desenvolveram sintomas.
Ressalta-se que algumas espécies de fungos possuem alta especificidade para determinadas plantas daninhas, o que representa grande seletividade de controle, todavia, a eficiência tende a ser maximizada em áreas com infestações monoespecíficas. Neste sentido, foi demonstrada alta especificidade do fungo Bipolaris euphorbiae (concentração de $1 \times 10^{7}$ esporos $\mathrm{ml}^{-1}$ ) em plantas de leiteiro (Euphorbia heterophylla), o qual induz sintomas (manchas necróticas nas folhas e caules) sete dias após a inoculação, sendo que, os autores observaram taxa de mortalidade de 80\% em plantas inoculadas (Nechet et al., 2006).

Espécies de fungos podem ainda, produzir metabólitos secundários, fitotoxinas, capazes de induzir sintomas nas espécies vegetais antes mesmo do patógeno se estabelecer e colonizar a planta hospedeira (Varejão et al., 2013). Utilizar os produtos metabólicos e não o organismo vivo pode se tornar prática viável, tendo em vista que o organismo vivo exige um ambiente altamente favorável que lhe proporcione desenvolver as estruturas necessárias para a colonização, e posterior infecção da planta hospedeira.

Como exemplo de herbicida comercial derivado que produtos de origem fúngicas, destaca-se o bialophos. Este produto é constituído pela fosfinotricina (aminoácido análogo ao ácido L-glutâmico) isolado da fermentação de culturas de Streptomyces hygroscopicus e S. viridochromogenes, e sendo comercializado como glufosinato de amônio (Dias e Dias, 2007; Dayan et al., 2009).

Além de fungos, outros organismos podem ser utilizados em estratégias alternativas no controle de plantas daninhas. De acordo com White et al. (2007), insetos predadores de sementes podem causar danos na biomassa de plantas daninhas, como exemplo de infestações do besouro Anisodactylus sanctaecrucis e do grilo Gryllus Pennsylvanicus que podem reduzir a emergência de plantas daninhas em até $15 \%$.

Apesar de escassos, têm-se relatos para o uso de vírus e bactérias no controle de plantas daninhas. Charudattan e Hiebert (2007), relatam 
que Solanum viarum, popularmente conhecida como joá-bravo, pode ser controlada pelo vírus Tobacco Mild Green Mosaic Vírus (Vírus do Mosaico Verde Leve do Tabaco-TMGMV), com eficiência de controle de $98-99 \%$ por meio de pulverizador de alta pressão. $\mathrm{O}$ vírus TMGMV induz resposta sistêmica, hipersensível na planta daninha, podendo ser utilizado como bioherbicida. Para bactérias, Chaves e Mitkoski (2013) observaram que a inoculação de concentrações superiores a $10^{7} \mathrm{Cfu} \mathrm{ml}^{-1}$ de Xanthomonas translucens pv. Poae, pode causar a morte da planta daninha Poa annua a partir de $2 \mathrm{~cm}$ de altura. Os autores determinaram que em condições ideais para o desenvolvimento da doença, isolados bacterianos podem causar até $100 \%$ de necrose foliar. Na Tabela 2, estão apresentados alguns exemplos de agentes biológicos com potenciais para a supressão de plantas daninhas em áreas agrícolas.

Tabela 2. Agentes biológicos com potencial de controle de plantas daninhas em áreas agrícolas.

\begin{tabular}{|c|c|c|c|}
\hline Agente Biológico & Planta Daninha & Principais efeitos na planta daninha & Referência \\
\hline $\begin{array}{l}\text { Stromatinia cepivora } \\
\text { (fungo) }\end{array}$ & Allium triquetrum & $\begin{array}{l}\text { Sintomas da doença observados após } \\
15 \text { dias da inoculação. }\end{array}$ & $\begin{array}{l}\text { Tehranchian et al. } \\
\text { (2014) }\end{array}$ \\
\hline $\begin{array}{l}\text { Alternaria euphorbiicola } \\
\text { (fungo) }\end{array}$ & $\begin{array}{c}\text { Euphorbia } \\
\text { heterophylla }\end{array}$ & $\begin{array}{l}\text { Sintomas necróticos visíveis após } 48 \\
\text { horas da inoculação. }\end{array}$ & Varejão et al. (2013) \\
\hline $\begin{array}{c}\text { Mycosphaerella } \\
\text { polygoni-cuspidati } \\
\text { (fungo) }\end{array}$ & Fallopia japonica & $\begin{array}{c}\text { Incidência da doença após a inoculação } \\
\text { entre } 78 \% \text { e } 100 \% \text {. }\end{array}$ & Kurose et al. (2015) \\
\hline $\begin{array}{l}\text { Myrothecium verrucaria } \\
\text { (fungo) }\end{array}$ & Sesbania exaltata & $\begin{array}{l}\text { Infecção e mortalidade a níveis de } \\
100 \% \text { em mudas de Sesbania cânhamo } \\
\text { dentro de } 48 \text { h após a inoculação. }\end{array}$ & Boyette et al. (2014) \\
\hline $\begin{array}{l}\text { Aspergillus alliaceus } \\
\text { (fungo) }\end{array}$ & Orobanche cernua & $\begin{array}{l}\text { Efeitos no número de tubérculos, } \\
\text { número de brotos: entre } 70 \% \text { a } 80 \% \text { em } \\
\text { relação ao controle. }\end{array}$ & Aibeke et al. (2014) \\
\hline $\begin{array}{c}\text { Pseudomonas fluorescens } \\
\text { BRG100 } \\
\text { (bactéria) }\end{array}$ & Setaria viridis & $\begin{array}{l}\text { Colonização da porção ventral do } \\
\text { revestimento de sementes, pêlos } \\
\text { radiculares e todas as áreas da raiz. } \\
\text { Atividade supressora no crescimento } \\
\text { de } S \text {. viridis. }\end{array}$ & Caldwell et al. (2012) \\
\hline $\begin{array}{c}\text { Pseudomonas syringae pv. tagetis } \\
\text { (bactéria) }\end{array}$ & Ambrosia grayi & $\begin{array}{c}\text { Parcelas inoculadas com sintomas em } \\
\text { torno de } 80 \% \text {, em comparação com a } \\
\text { testemunha }(0 \%) \text {. }\end{array}$ & Sheikh et al. (2001) \\
\hline $\begin{array}{c}\text { Araujia mosaic virus (ArjMV) } \\
\text { (vírus) }\end{array}$ & Araujia hortorum & $\begin{array}{l}\text { Sintomas de mosaico, manchas } \\
\text { cloróticas e distorção foliar. Atraso no } \\
\text { crescimento da planta daninha. }\end{array}$ & Elliot et al. (2009) \\
\hline $\begin{array}{c}\text { Tyria jacobaeae (L.) } \\
\text { (Lepidoptera: Arctiidae) } \\
\text { (inseto) }\end{array}$ & Senecio jacobaea & $\begin{array}{c}\text { Lançamento de } 1000 \text { e } 2000 \text { larvas em } \\
\text { dois anos, expandem a população ao } \\
\text { nível de causar a desfolha da planta } \\
\text { daninha. }\end{array}$ & $\begin{array}{l}\text { Markin e Littlefield } \\
\qquad(2008)\end{array}$ \\
\hline $\begin{array}{c}\text { Neochentina eichorniae } \\
\text { (Coleoptera: Curculionidae) } \\
\text { e Eccritotarsus catarinensis } \\
\text { (Heteroptera: Miridae) } \\
\text { (inseto) }\end{array}$ & $\begin{array}{l}\text { Eichhornia } \\
\text { crassipes }\end{array}$ & $\begin{array}{l}\text { A alimentação de adultos e a formação } \\
\text { de túneis por larvas causam impacto } \\
\text { significativo no vigor e reprodução da } \\
\text { planta daninha, reduzindo em cerca de } \\
70 \% \text { no peso fresco. }\end{array}$ & Ajuonu et al. (2009) \\
\hline $\begin{array}{c}\text { Neohydronomus affinis } \\
\text { (Coleoptera:Curculionidae) } \\
\text { (inseto) }\end{array}$ & Pistia stratiotes & $\begin{array}{l}\text { Sob condições laboratoriais, um casal } \\
\text { por planta foi considerado suficiente } \\
\text { para efetuar o controle da planta } \\
\text { daninha no período de seis semanas. }\end{array}$ & Diop et al. (2010) \\
\hline
\end{tabular}


Vários fatores afetam a eficácia dos agentes biológicos como bioherbicidas como a umidade do ar e do solo, o método de aplicação, o espectro controle e o tipo de formulação, sendo que estes fatores limitam sua aplicação a campo, além da eficácia, os custos e preocupações sobre possíveis impactos para a saúde humana também são limitações para o uso de bioherbicidas (Cai e Gu, 2016). Entretanto, o aprimoramento da tecnologia de bioherbicidas para uso no manejo integrado das plantas daninhas pode reduzir os custos de produção e aumentar o rendimento das culturas em sistemas agroecológicos, como também, pode evitar a seleção de espécies resistentes aos herbicidas em sistemas convencionais de produção.

\section{Controle mecânico automatizado}

O controle mecânico consiste no uso de medidas que causam a destruição direta das plantas daninhas. Nesse tipo de controle as ferramentas mais utilizadas são tracionadas pelo homem, animal ou máquinas (Silva et al., 2011b). No Brasil ainda são escassas as informações na literatura sobre a utilização de equipamentos para o controle mecânico de planta daninha em sistemas orgânicos, entretanto, se destacam os avanços da tecnologia dos capinadores mecânicos, nos países em que há grande número de produtores orgânicos.

O controle mecânico com sistemas automatizados apresenta-se como excelente alternativa para o controle das plantas daninhas tanto em áreas com dependência do uso de herbicidas quanto em áreas em que a remoção manual das plantas daninhas ainda é realizada (Fennimore et al., 2016). A automatização do controle das plantas daninhas apresenta dois aspectos-chave, a detecção de culturas/plantas daninhas e os sistemas de controle das plantas daninhas. A detecção automática permite que máquinas comerciais reconheçam padrões de linhas de culturas e controlem dispositivos automatizados que executam o controle das plantas daninhas nas entrelinhas sem reduzir o estande da cultura ou ralear a linha de semeadura da cultura (Ascard e Fogelberg, 2008; Fennimore et al., 2014).
Os equipamentos de capina mecanizada podem ser guiados com sistemas de precisão para orientação automática do trator, como câmeras de vídeo com sistema de detecção em tempo real (Real-Time Kinematic-RTK), sistemas GPS (Global Positioning Systems) ou a combinação de ambos sistemas de detecção e mapeamento (Pérez-Ruiz et al., 2012). Enquanto que para o controle das plantas daninhas na linha e entrelinha da cultura são usadas ferramentas especiais como dedos/hastes flexíveis, enxadas rotativas ou sistemas de mini enxadas ou facas adaptadas, acionadas por meio de sistemas hidráulicos ou pneumáticos.

Estes equipamentos estão sendo desenvolvidos para uso em sistemas convencional com revolvimento do solo sem a presença de palhada como cobertura vegetal. Entretanto, no Brasil, como forma de permitir a utilização de capinadoras automatizadas em sistemas de plantio direto, o Núcleo de Pesquisa em Agroecologia da Universidade Estadual do Oeste do Paraná está realizando avaliações de adaptações na capinadora guiada por câmera de vídeo modelo ROW-GUARD CHOPSTAR, a qual sendo adaptada para condições de semeadura direta com palhada (Comunicação pessoal). A adaptação corresponde a disposição na plataforma hidráulica de um conjunto de 10 discos de corte (diâmetro de $42 \mathrm{~cm}$ ) que passam fatiando horizontalmente a $5 \mathrm{~cm}$ o perfil do solo nas entre linhas da cultura e na frente de cada disco horizontal, foi disposto um disco de corte da palhada (Figura 1). Desta forma, a manutenção da palhada na entrelinha da cultura pode contribuir na supressão do banco de sementes devido ao efeito físico e da liberação de compostos alelopaticos e portanto, auxiliar no manejo integrado das plantas daninhas após a utilização de capinadoras automatizadas.

De acordo com Pérez-Ruiz et al. (2014), a média de horas/pessoa necessária para controlar as plantas daninhas manualmente em $100 \mathrm{~m}^{2}$ foi de $0,241 \mathrm{~h}$, enquanto que o co-robô (cultivador automatizado adaptado para o controle na linha e entrelinha, com sistema de detecção em tempo 

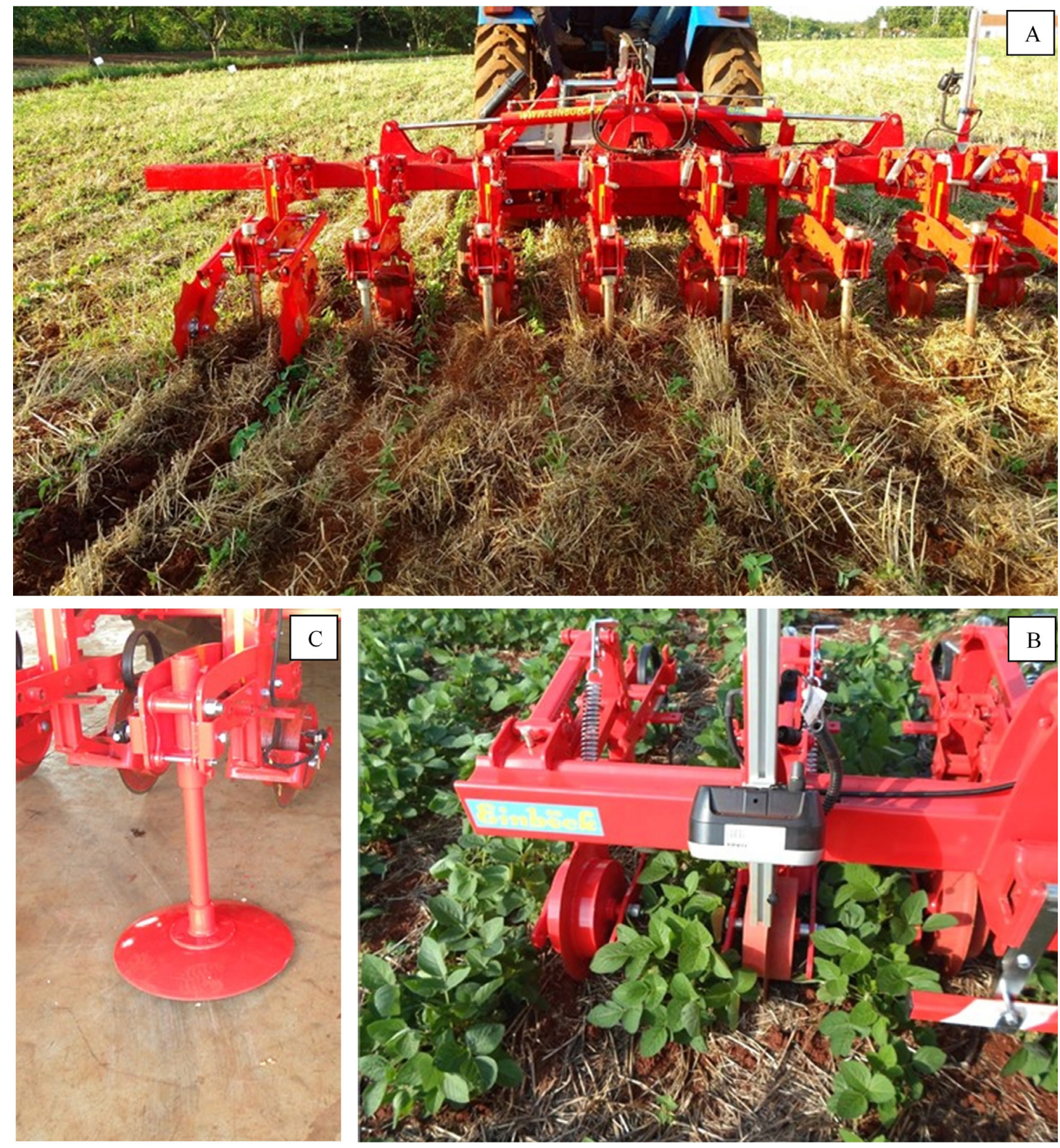

Figura 1. Capinadora guiada por câmera de vídeo adaptada para uso em áreas de semeadura direta. A: Capinadora automatizada modelo ROW-GUARD CHOPSTAR (Einböck) com discos de cortes horizontais giratórios. B: Câmera de vídeo para detecção da linha da cultura. C: Disco de corte horizontal (diâmetro de $42 \mathrm{~cm}$ ) utilizado no controle das plantas daninhas, fatiando a $5 \mathrm{~cm}$ o perfil do solo nas entre linhas da cultura.

real e resposta pneumática, baseada em uma técnica de odometria) gastou apenas $0,102 \mathrm{~h}$ para manejar a mesma área. Isso representou redução de 57,5\% nas exigências de mão-de-obra para o controle de plantas daninhas e indica o potencial de uso do controle mecanizado automatizado. Lati et al. (2016), verificaram que o Robovator (cultivador com sistema de câmera de detecção de plantas) removeu de 18 a $41 \%$ mais plantas daninhas em densidades moderadas a altas, 
respectivamente e reduziu os tempos de remoção manual de 20 a 45\% em comparação com o cultivador padrão (sem sistema de detecção de plantas). Os autores citaram ainda que o Robovator não reduziu o rendimento de colheita ou comercializável do Brócolis (Brassica oleracea L.) em comparação com o cultivador padrão.

Segundo Silva et al. (2005), o preparo continuo com o controle mecânico pode promover a diminuição do banco de sementes no solo. No entanto, Jakelaitis et al. (2003) relataram que o manejo contínuo do solo pode aumentar a infestação espécies que se propagam vegetativamente. Bem como, apresenta baixo rendimento, demanda muita mão de obra e custo elevado, além de que pode prejudicar as raízes superficiais das culturas (Ronchi et al., 2010). E ainda pode contribuir para erosão do solo.

Oneto et al. (2010), ao utilizar o controle mecânico com equipamento de corte aéreo das plantas daninhas observaram eficiência de $80 \%$ de controle da comunidade infestante. Entretanto, estes autores relatam que esta técnica só seria eficaz se as plantas não apresentar potencial de rebrota ou são incapaz de rebrotar sob algum tipo de fator abiótico (estresse hídrico) ou associado com o tempo de controle.

De acordo com Fennimore et al. (2016), futuras estratégias de controle das plantas daninhas provavelmente exigirão a adaptação das culturas ao equipamento de controle mecânico automatizado. Um exemplo seria a necessidade de mudanças nos padrões de semeaduras e de espaçamento das culturas para facilitar o controle em duas direções, além de adequações na arquitetura da planta. Da mesma forma, Lati et al. (2016), citam que os avanços tecnológicos e as reduções de preços desses tipos de equipamentos provavelmente melhorarão a eficácia de controle e a viabilidade a longo prazo dos programas de manejo integrado das plantas daninhas.

\section{Controle térmico}

O controle térmico com o uso do calor destacase dentre as principais técnicas adotada no controle físico. O controle térmico das plantas daninhas anuais pode ser $22,5 \%$ mais eficiente do que o método mecânico (Virbickaite et al., 2006). Esta técnica também pode ser utilizada na dessecação culturas com a batata no período da colheita (Silva, 2007).

Segundo Silva (2008), o controle térmico com uso flamejadores expandiu-se como técnica de controle sendo aplicada principalmente em faixas sobre as plantas daninhas que se desenvolviam nas entre linhas das plantas cultivadas, entretanto, o uso desta técnica apresenta limitações em função da cobertura vegetal e manejo do solo e das condições climáticas no momento em que são utilizados.

Os flamejadores usados no controle de plantas daninhas são ferramentas que utilizam queimadores dispostos numa barra, sendo que para a aplicação de chama dirigida na entrelinha da cultura os queimadores podem ser protegidos, enquanto que para a aplicação em área total não há a necessidade de proteção dos queimadores.

Existem vários modelos de equipamentos utilizados em diversos países. Porém, no Brasil apenas em 2008 a técnica do flamejamento foi permitida por meio da Instrução Normativa no 64 de 18/12/2008 (Burin e Fuentes, 2015). A falta de interesse das empresas em fabricar o equipamento faz com que os produtores e pesquisadores utilizem equipamentos artesanais os chamados lança-chamas. Além disso, ao utilizar o lança-chamas ocorre o risco de acidentes com o operador, queima dos cultivos comerciais pela falta de precisão do equipamento e elevado custo com combustível.

Segundo Rifai et al. (2003), o flamejamento controla as plantas daninhas por meio de calor intenso, aquecendo as plantas de forma rápida e sem causar injúrias as culturas. Esta técnica causa dessecação das plantas devido a desnaturação das membranas e de proteínas sem que as plantas sejam consumidas pela ação do fogo. 
Taylor et al. (2012), citam que o uso de flamejadores a base de propano poderia fornecer benefício econômico para os produtores orgânicos nos casos em períodos chuvosos impeçam o controle mecânico das plantas daninhas e de mão de obra escassa. Da mesma forma, os autores verificaram que o flamejador reduziu as densidades de plantas daninhas de folha larga (Chenopodium album, Portulaca oleracea, Ambrosia artemisiifolia, Amaranthus retroflexus) e Abutilon theophrasti) em cerca de $82 \%$ quando feito de manhã até meio da tarde ( 8 as $16 \mathrm{~h})$, mas apenas reduziu as densidades em 58\% quando as espécies foram controladas a noite (20h).

Silva (2008), testou flamejadores de radiação direta para controle de duas espécies de folha larga (Bidens pilosa L. e Ipomea triloba L.) e duas espécies de folha estreita (Brachiaria decumbens Stapf e Panicum maximum Jacq.) e verificaram elevada eficiência de controle, sendo para $B$. pilosa o controle foi de $100 \%$. Em trabalho realizado por Favarato et al. (2016), com plantas de Bidens pilosa, Digitaria sanguinalis, Euphorbia heterophylla, Galinsoga quadriradiata, Oxalis spp. e Sonchus oleraceus, a aplicação da chama por $10 \mathrm{~s} \mathrm{~m}^{-2}$ foi eficiente e reduziu cerca de $86,7 \%$ a porcentagem de infestação. Vale ressaltar a possibilidade da ocorrência de tolerância diferencial de espécies ao controle térmico.

Existem outras opções no controle térmico a exemplo de rio laser, de água quente, vapor, óleo quente e descarga elétrica. Kaierle et al. (2013), observaram excelente potencial de controle da planta daninha Amaranthus retroflexus com o uso de radiação a laser (25 J por planta). Já Pinel et al. (2000), observaram controle de $98 \%$ das plantas daninhas com a utilização de vaporização.

Como opção de controle alternativo das plantas daninhas a COOPERBIOBRASIL (Cooperativa Solidaria Mista de Produção Agroecologica e de
Equipamentos Ambientais, Importação e Exportação, situada em Mandirituba/PR) está desenvolvendo um protótipo que utiliza um sistema de controle térmico utilizando óleo vegetal (ECOCAPINA) capaz de substituir a capina manual ou mecânica e o uso de herbicidas (Comunicação pessoal). $\mathrm{O}$ mecanismo de funcionamento da Ecocapina está baseado no controle térmico, sendo que o calor $\left(100^{\circ} \mathrm{C}\right)$ aplicado por menos de um segundo provoca a ruptura das membranas celulares, "coagulando" a seiva e promovendo a secagem da planta em até três dias. Do mesmo modo, o equipamento Eletroherb (Sayyou do Brasil) que produz descargas elétricas e está sendo utilizado para o controle de plantas daninhas em área urbanas, apresenta excelente potencial para o manejo de dessecação de plantas de cobertura, bem como, no controle dirigido das plantas daninhas presentes nas entrelinhas das culturas (Figura 2). De acordo com Brighenti e Brighenti (2009), o emprego de descarga elétrica foi eficiente no controle das plantas daninhas nas entrelinhas da cultura da soja, sendo que a rotação $2200 \mathrm{rpm}$ (4400 Volts) proporcionou o melhor controle e, consequentemente, a maior produtividade da cultura da soja.

Apesar de eficiente, o Eletroherb deve ser utilizado para a dessecação quando as plantas estão verdes ou nos primeiros horários do dia com presença de orvalho, enquanto que, em horários mais quentes do dia e quando a palha está muito seca, pode-se utilizar um pulverizador emergencialmente, para evitar o surgimento de focos de incêndios (Figura 3). Outro ponto importante, refere-se que a eficiência do controle térmico dura em média de 2 a 4 semanas, o que pode exigir a utilização com maior frequência por parte do produtor para evitar as reinfestações ou rebrotes. Assim, o uso do controle térmico em sistemas orgânicos pode promover danos na biologia do solo e a entomofauma existente, sendo necessários 

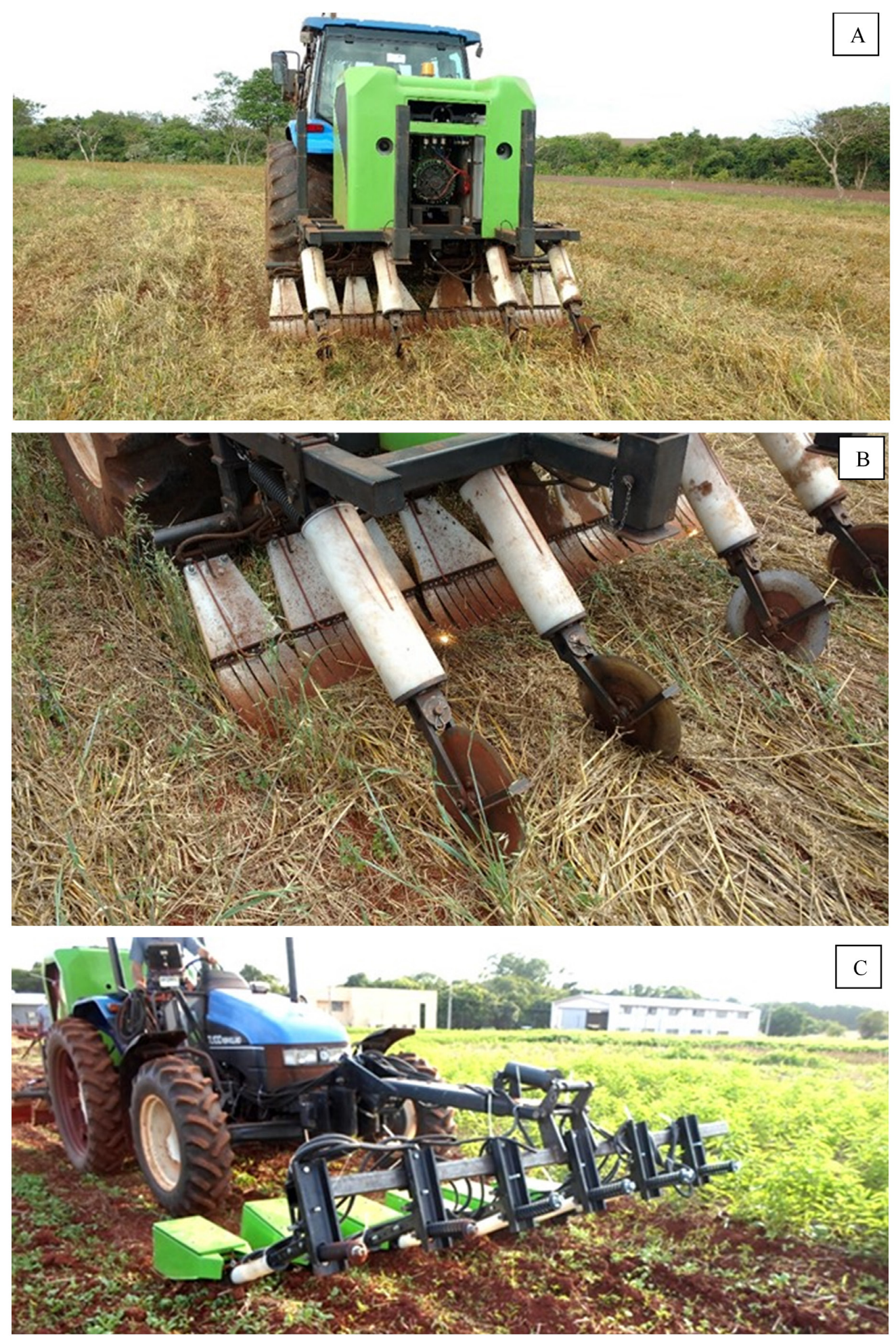

Figura 2. Equipamento Eletroherb que produz descargas elétricas. A: Utilização do Eletroherb na dessecação da cultura da aveia e controle das plantas daninhas em áreas agroecológicas. B: Funcionamento do mecanismo de descarga elétrica sobre as plantas e C: Eletroherb adaptado para o controle das plantas daninhas nas entre linhas de culturas anuais. 

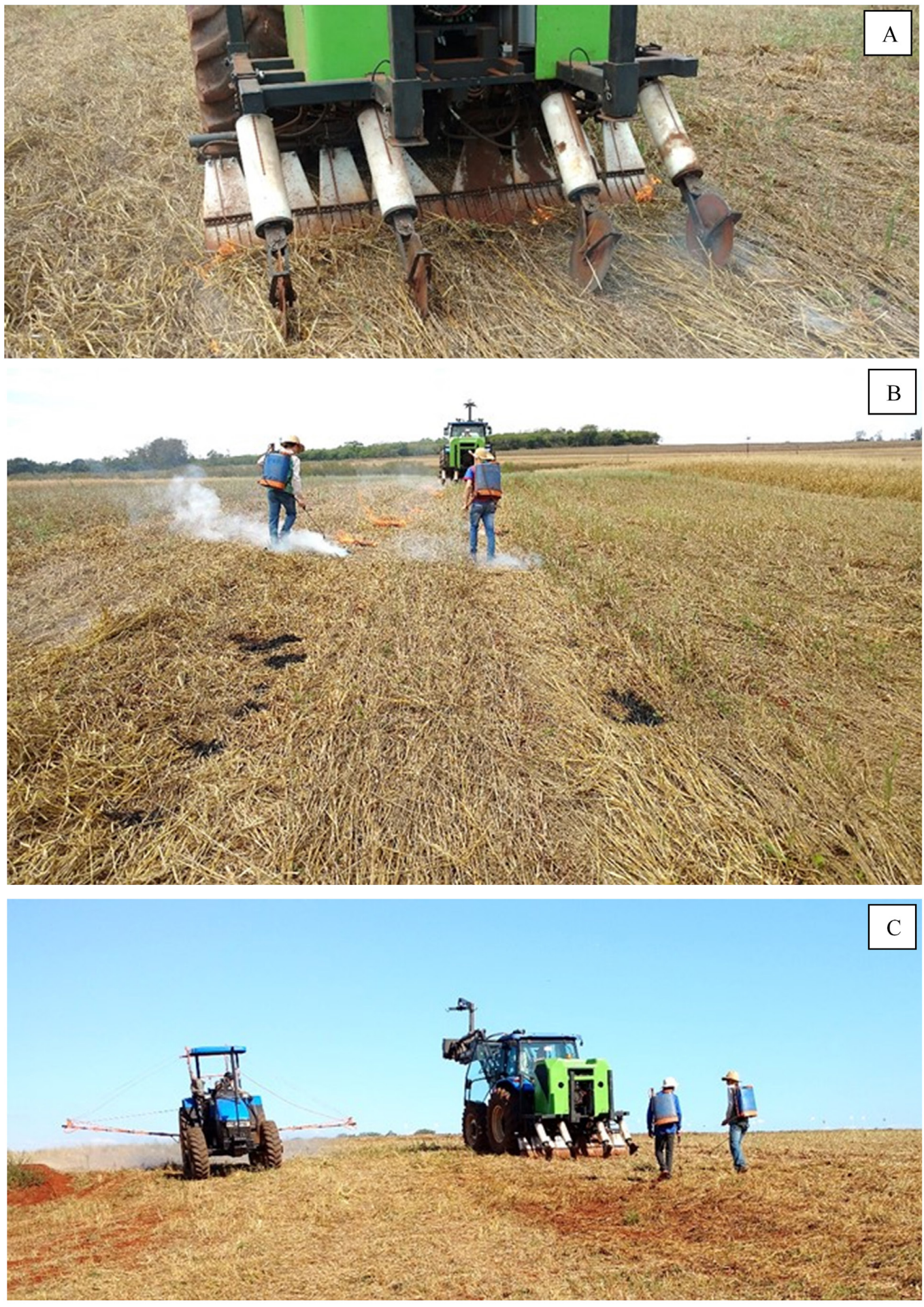

Figura 3. Utilização do equipamento Eletroherb em período de baixa umidade relativa do ar e alta temperatura na dessecação da área antes da semeadura da soja orgânica. A: Princípio de incêndio durante a dessecação da cultura da aveia e do controle das plantas daninhas. B: Eliminação manual dos focos de incêndios e C: Pulverização de água antes da dessecação das plantas daninhas para evitar os focos de incêndios. 
estudos de longo prazo para a verificação dos possíveis impactos ambientais.

\section{Considerações finais}

As novas demandas ambientais, sociais e econômicas, vêm exigindo dos produtores rurais uma reflexão quando se trata da produção de alimentos sem o uso de agrotóxicos. Deste modo, dentre os desafios encontrados ressalta-se o controle das plantas daninhas, bem como a escassez de mão de obra que reflete em elevados custos para a realização da capina manual.

Em sistemas orgânicos de produção, podem ser adotados métodos de controle baseados em estratégias culturais (variedades competitivas, redução de espaçamentos, densidades de semeadura, plantas de cobertura, etc.), biológicos (utilização de agentes biológicos, toxinas ou compostos alelopáticos como bioherbicidas), mecânicos (novas capinadoras automatizados com sistemas de detecção da cultura e das plantas daninhas, sistemas robóticos) e físicos (monda térmica, elétrica ou com outras fontes de energia). Porém, são necessários mais estudos para viabilizar o emprego das novas tecnologias principalmente em grandes áreas e a baixo custo.

De acordo com Abouziena e Haggag (2016), os produtores de agricultura orgânica devem considerar três aspectos no controle das plantas daninhas: evitar as infestações iniciais simultâneas a emergência da cultura e manter limpo de forma bem-sucedida; a prevenção é sempre melhor do que o tratamento; e as sementes de um ano conduzirão à infestação por plantas daninhas durante sete anos. Entretanto, a utilização sistemática de apenas um método de controle na mesma área e por longo tempo, além de ser pouco eficiente pode selecionar espécies adaptadas ou tolerantes ao método, semelhante ao que ocorre no controle químico.

Portanto, para o sucesso do controle das plantas daninhas em áreas orgânicas deve-se utilizar de modo sustentável as estratégias integradas de manejo. Do mesmo modo, são necessários mais conhecimento sobre as relações biológicas e ecológicas que determinam o grau de interferências entre as espécies infestantes e cultivadas em áreas orgânicas, além dos impactos a médio e longo prazo das novas tecnologias de controle sobre aspectos ambientais e socioeconômicos.

\section{Referências}

Abouziena, H.F.; Haggag, W.M. Weed control in clean agriculture: a review1. Planta Daninha, v.34, n.2, p.377-392, 2016.

Agostinetto, D.; Rigoli, R.P.; Schaedler, C.E.; Tironi, S.P.; Santos, L.S. Período crítico de competição de plantas daninhas com a cultura do trigo. Planta Daninha, v.26, n.2, p.271-278, 2008.

Aibeke, M.; Sen, B.; Öken, S. Aspergillus alliaceus, a new potential biological control of the root parasitic weed Orobanche. Journal of Basic Microbiology, v.54, n.2, p.93-101, 2014. Ajuonu, O.; Byrne, M.; Hill, M. The effect of two biological control agents, the weevil Neochetina eichhorniae and the mirid Eccritotarsus catarinensis on water hyacinth, Eichhornia crassipes, grown in culture with water lettuce, Pistia stratiotes. BioControl, v.54, n.1, p.155-162, 2009.

Ascard, J.; Fogelberg, F. Mechanical intra-row weed control in direct-sown and transplanted bulb onions. Biological Agriculture and Horticulture, v.25, n.3, p.235-251, 2008.

Ash, G.J. The science art business of succeful bioherbicides. Biological Control, v.52, n.3, p.230-240, 2010.

Bajwa, A.A.; Mahajan, G.; Chauhan, B.S. Nonconventional weed management strategies for modern agriculture. Weed Science, v.63, n.4, p. 723-747, 2015.

Bittencourt, H.H.; Franzener, G. Potenciais agentes de controle biológico de plantas espontâneas em agroecossistemas no estado do Paraná. Revista 
Verde de Agroecologia e Desenvolvimento Sustentável, v.8, n.5, p.158-162, 2013.

Borchartt, L.; Jakelaitis, A.; Valadão, F.C.A.; Venturoso, L.A.C.; Santos, C.L. Períodos de interferência de plantas daninhas na cultura do feijoeiro-comum (Phaseolus vulgaris L.). Revista Ciência Agronômica, v.42, n.3, p.725-734, 2011.

Boyette, C.D.; Hoagland, R.E.; Stetina, K.C. Biological control of the weed hemp sesbania (Sesbania exaltata) in rice (Oryza sativa) by the fungus Myrothecium verrucaria. Agronomy, v.4, n. 1, p.74-89, 2014.

Brighenti, A.M.; Brighenti, D.M. Controle de plantas daninhas em cultivos orgânicos de soja por meio de descarga elétrica. Ciência Rural, v.39, n.8, p.2315-2319, 2009.

Burin, P.C.; Fuentes, L.F.G. Uso do fogo como alternativa no controle de plantas daninhas. Revista electrónica de Veterinária, v.16, n.8, p.1-13, 2015.

Cai, X.; Gu, M. Bioherbicides in organic horticulture. Horticulturae, v.2, n.2, p.1-10, 2016.

Caldwell, C.J.; Hynes, R.K.; Boyetchko, S.M.; Korber, D.R. Colonization and bioherbicidal activity on green foxtail by Pseudomonas fluorescens BRG100 in a pest a formulation. Canadian Journal of Microbiology, v.58, n.1, p.1-9, 2012. Carvalho, W.P.; Teixeira, L.G.V.; Abbade Neto, D.O.; Moreira, J.M.S.; Cunha, C.E. Alelopatia de resíduos de plantas de cobertura no controle de braquiária cv. Marandu. Revista Brasileira de Biociências, v.14, n.2, p.60-69, 2016.

Charudattan, R.; Hiebert, E. A plant virus as a bioherbicide for tropical soda apple, Solanum viarum. Outlooks on Pest Management, v.18, n.4, p.167-171, 2007.

Chaves, A.; Mitkoski, N. Virulence of Xanthomonas translucens pv. poae Isolated from Poa annua. The Plant Pathology Journal, v.1, n.29, p.9398, 2013.
Cisneros, J.J.; Zandstra, B.H. Flame weeding effects on several weed species. Weed Technology, v.22, n.2, p.290-295, 2008.

Correia, N.M.; Durigan, J.C.; Klink, U.P. Influência do tipo e da quantidade de resíduos vegetais na emergência de plantas daninhas. Planta Daninha, v.24, n.2, p.245-253, 2006.

Corsato, J.M.; Fortes, A.M.T.; Santorum, M.; Leszczynski, R. Efeito alelopático do extrato aquoso de folhas de girassol sobre a germinação de soja e picão-preto. Semina: Ciências Agrárias, v.31, n.2, p.353-360, 2010.

Dayan, F.E.; Cantrel, I.C.L.; Duke, S.O. Natural products in crop protection. Bioorganic \& Medicinal Chemistry, v.17, n.12, p.4022-4034, 2009.

Dias, L.S.; Dias, A.S. Metabolitos secundários como fontes de bioherbicidas: situação actual e perspectivas. Revista de Ciências Agrárias, v.30, n.1, p.510-517, 2007.

Diop, O.; Coetzee, J.A.; Hill, M.P. Impact of different densities of Neohydronomus affinis (Coleoptera:Curculionidae) on Pistia stratiotes (Araceae) under laboratory conditions. African Journal of Aquatic Science, v.35, n.3, 2010.

Duke, S.O. Proving allelopathy in crop-weed interactions. Weed Science, v.63, n.special, p.121-132, 2015.

Elliot, M.S.; Massey, B.; Cui, X.; Hiebert, E.; Charudattan, R.; Waipara, N.; Hayesc, L. Supplemental host range of Araujia mosaic virus, a potential biological control agent of moth plant in New Zealand. Australasian Plant Pathology, v.38, n.6, p.603-607, 2009.

Favarato, L.F.; Souza, J.L.; Guarconi, R.C. Bahiense, D. Flamethrower application time in weed control. Planta Daninha, v.34, n.2, p.327332, 2016.

Fennimore, S.A.; Slaughter, D.C.; Siemens, M.C.; Leon, R.G.; Saber, M.N. Technology for 
automation of weed control in specialty crops. Weed Technology, v.30, n.4, p.823-837, 2016.

Fennimore, S.A.; Smith, R.F.; Tourte, L.; LeStrange, M.; Rachuy, J.S. Evaluation and economics of a rotating cultivator in bok choy, celery, lettuce, and radicchio. Weed Technology, v.28, n.1, p.176-188, 2014.

Ferreira, A.G.; Aquila, M.E.A. Alelopatia: uma área emergente da ecofisiologia. Revista Brasileira de Fisiologia Vegetal, v.12, p.175-204, 2000. Edição especial.

Galon, L.; Mossi, A.; Reichert Junior, F.; Reik, G.; Treichel, H.; Forte, C. Manejo biológico de plantas daninhas - breve revisão. Revista Brasileira de Herbicidas, v.15, n.1, p.116-125, 2016.

Gantoli, G.; Ayala, V.R.; Gerhards, R. Determination of the Critical Period for Weed Control in Corn. Weed Technology, v.27, n.1, p.63-71, 2013.

Hagemann, T.R.; Benin, G.; Lemes, C.; Marchese, J.A.; Martin, T.N.; Pagliosa, E.S.; Beche, E. Potencial alelopático de extratos aquosos foliares de aveia sobre azevém e amendoim-bravo. Bragantia, v.69, n.3, p.509-518, 2010.

Hallett, S.G. Where are the bioherbicides? Weed Science, v.53, n.3, p.404-415, 2005.

Hong, S.H.; Choi, Y.J.; Cho, S.E.; Park, J.H.; Shin, H.D. First report of powdery mildew caused by golovinomyces cichoracearum on tragopogon dubius in korea. Plant Disease Journal, v.100, n. 7, p.1496, 2016.

Jakelaitis, A.; Ferreira, L.R.; Silva, A.A.D.; Agnes, E.L.; Miranda, G.V.; Machado, A.F.L. Dinâmica populacional de plantas daninhas sob diferentes sistemas de manejo nas culturas de milho e feijão. Planta Daninha, v.21, n.1, p.71-79, 2003.

Kaierle, S.; Marx, C.; Rath, T.; Hustedt, M. Find and irradiate-lasers used for weed control. LaserTechnik-Journal, v.10, n.3, p.44-47, 2013.

Kato-Noguchi, H.; Kobayashi, A.; Ohno, O.; Kimura, F.; Fujii, Y.; Suenaga, K. Phytotoxic substances with allelopathic activity may be central to the strong invasive potential of Brachiaria brizantha. Journal of Plant Physiology, v.171, p.525-530, 2014.

Klein, A.; Felippe, G.M. Efeito da luz na germinação de sementes de ervas invasoras. Pesquisa Agropecuária Brasileira, v.26, n.7, p.955-966, 1991.

Knezevic, S.Z.; Stepanovic, S.; Datta, A. Growth stage affects response of selected weed species to flaming. Weed Technology, v.28, n.1, p.233242, 2014.

Kurose, D.; Furuya, N.; Seier, M.K.; Djeddour, D.H.; Evans, H.C.; Matsushita, Y.; et al. Factors affecting the efficacy of the leaf-spot fungus Mycosphaerella polygoni-cuspidati (Ascomycota): a potential classical biological control agent of the invasive alien weed Fallopia japonica (Polygonaceae) in the UK. Biological Control, v.85, p.1-11, 2015.

Lamego, F.P.; Kaspary, T.E.; Ruchel, Q.; Gallon, M.; Basso, C.J.; Santi, A.L. Manejo de Conyza bonariensis resistente ao glyphosate: coberturas de inverno e herbicidas em pré-semeadura da soja. Planta Daninha, v.31, n.2, p.433-442, 2013.

Lati, R.N.; Siemens, M.C.; Rachuy, J.S.; Fennimore, S.A. Intrarow weed removal in broccoli and transplanted lettuce with an intelligent cultivator. Weed Technology, v.30, n.3, p.655-663, 2016.

Lima, B.V.L.; Soares, D.J.; Barreto, R.W. Inoculum density of Plectosporium alismatis, a potential mycoherbicide, in relation to control of the aquatic weed Sagittaria montevidensis. Tropical Plant Pathology, v.35, n.4, p.236-240, 2010.

Machado, A.C.R.; Mochi, A.; Monteiro, A.C. Crop optimization and pre-steps standardization to get a Bipolaris euphorbiae-based bioherbicide. Pesquisa Agropecuária Tropical, v.43, n.4, p.392-399, 2013.

Mahmood, A.; Khaliq, A.; Ihsan, M.Z.; Naeem, M.; Daur, I.; Matloob, A.; El-Nakhlawy, F.S. 
Estimation of weed dry biomass and grain yield as a function of growth and yield traits under allelopathic weed management in maize. Planta Daninha, v.33, n.1, p.23-31, 2015.

Markin, G.P.; Littlefield, J.L. Biological control of tansy ragwort (Senecio jacobaeae L.) by the cinnabar moth, Tyria jacobaeae (CL) (Lepidoptera: Arctiidae), in the northern Rocky Mountains. In: Julien, M.H.; Sforza, R.; Bom, M.C.; Evans, H.C.; Hatcher, P.E.; Hinz, H.L.; Rector, B.G. (Eds.). XII International Symposium on Biological Control of Weeds, 12., 22-27 April 2007, La GrandeMotte, France. Proceedings..., Wallingford: CAB International, 2008. p.583-588.

Melander, B.; Rasmussen, I.A.; Bàrberi, P. Integrating physical and cultural methods of weed control-examples from European research. Weed Science, v.53, n.3, p.369-381, 2005.

Melo, A.V.; Galvão, J.C.C.; Ferreira, L.R.; Miranda, G.V.; Santos, L.D.T.; Santos, I.C.; Souza, L.V. Dinâmica populacional de plantas daninhas em cultivo de milho-verde nos sistemas orgânico e tradicional. Planta Daninha, v.25, n.3, p.521527, 2007.

Mitchell, G.; Bartlett, D.W.; Fraser, T.E.; Hawkes, T.R.; Holt, D.C.; Townson, J.K.; Wichert, R.A. Mesotrione: a new selective herbicide for use in maize. Pest Management Science, v.57, n.2, p.120-128, 2001.

Mizuno, A. Biological and agricultural studies on application of discharge plasma and electromagnetic fields. Destruction of weeds by high voltage discharge. Journal of Plasma and Fusion Research, v.75, n.6, p.666-671, 1999.

Mondo, V.H.V.; Carvalho, S.J.P.; Dias, A.C.R.; Filho, J.M. Efeitos da luz e temperatura na germinação de sementes de quatro espécies de plantas daninhas do gênero Digitaria. Revista Brasileira de Sementes, v.32, n.1, p.131-137, 2010.
Monquero, P.A.; Amaral, L.R.; Inácio, E.M.; Brunhara, J.P.; Binha, D.P.; Silva, P.V.; Silva, A.C. Efeito de adubos verdes na supressão de espécies de plantas daninhas. Planta Daninha, v.27, n.1, p.85-95, 2009.

Monquero, P.A.; Hijano, N.; Orzari, I.; Sabbag, R.S.; Hirata, A.C.S. Profundidade de semeadura, $\mathrm{pH}$, textura e manejo da cobertura do solo na emergência de plântulas de Rottboellia exaltata. Semina: Ciências Agrárias, v.33, n.1, p.27992812, 2012.

Moraes, C.; Monteiro, A.C.; Machado, A.C.R.; Barbosa, J.C.; Mochi, D.A. Production of a bioherbicide agent in liquid and solid medium and in a biphasic cultivation system. Planta Daninha, v.32, n.2, p.255-264, 2014.

Müller-Stover, D.; Kohlschmid, E.; Sauerborn, J. A novel strain of Fusarium oxysporum from Germany and its potential for biocontrol of Orobanche ramosa. Weed Research European, v.49, n.2, p.175-182, 2009.

Nechet, K.L.; Barreto, R.W.; Mizubuti, E.S.G. Bipolaris euphorbiae as a biological control agent for wild poinsettia (Euphorbia heterophylla): host-specificity and variability in pathogen and host populations. BioControl, v.51, n.2, p.259274, 2006.

Nepomuceno, M.; Alves, P.L.C.A.; Dias, T.C.S.; Pavani, M.C.M.D. Períodos de interferência das plantas daninhas na cultura da soja nos sistemas de semeadura direta e convencional. Planta Daninha, v.25, n.1, p.43-50, 2007.

Noce, M.A.; Souza, I.F.; Karam, D.; França, A.C.; Maciel, G.M. Influência da palhada de gramíneas forrageiras sobre o desenvolvimento da planta de milho e das plantas daninhas. Revista Brasileira de Milho e Sorgo, v.7, n.3, p.265-278, 2008.

Oneto, S.R.; Kyser, G.B.; DiTomaso, J.M. Efficacy of mechanical and herbicide control methods for Scotch broom (Cytisus scoparius) and cost analysis 
of chemical control options. Weed Science, v.03, n.4, p.421-428, 2010.

Perez-Ruiz, M.; Slaughter, D.C.; Fathallah, F.A.; Gliever, C.J.; Miller, B.J. Co-robotic intra-row weed control system. Biosystems Engineering, v.126, p.45-55, 2014.

Pérez-Ruiz, M.; Slaughter, D.C.; Gliever, C.J.; Upadhyaya, S.K. Automatic GPS-based intra-row weed knife control system for transplanted row crops. Computers and Electronics in Agriculture, v.80, p.41-49, 2012.

Peron, F.; Bonini, E.A. Utilização de leucena (Leucaena leucocephala) como alternativa de controle de picão preto (Bidens pilosa L.). In: VI Mostra Interna de Trabalhos de Iniciação Cientifica, 6., 2012, Maringá, PR. Anais... Maringá: CESUMAR, 2012. 15p.

Pinel, M.P.C.; Bond, W.; White, J.G. Control of soil-borne pathogens and weeds in leaf salad monoculture by use of a self-propelled soilsteaming machine. Acta Horticulturae, n.532, n.14, p.125-130, 2000.

Pires, N.M.; Prates, H.T.; Pereira Filho, I.A.; Oliveira Júnior, R.S.; Faria, T.C.L. Atividade alelopática da leucena sobre espécies de plantas daninhas. Scientia Agrícola, v.58, n.1, p.61-65, 2001.

Pitelli, R.; Durigan, J.C. Ecologia das plantas daninhas no sistema de plantio direto. In: Rossello, R.D. Siembra directa en el Cono Sur. Montevideo: PROCISUR, 2001, p.203-210.

Queiroz, L.R.; Galvão, J.C.C.; Cruz, J.C.; Oliveira, M.F.; Tardin, F.D. Supressão de plantas daninhas e produção de milho-verde orgânico em sistema de plantio direto. Planta Daninha, v.28, n.2, p.263-270, 2010.

Rask, A.M.; Kristoffersen, P. A review of nonchemical weed control on hard surfaces. Weed Research, v.47, n.5, p.370-380, 2007.
Reigosa, M.; Gomes, A.S.; Ferreira, A.G.; Borghetti, F. Allelopathic research in Brazil. Acta Botanica Brasílica, v.27, n.4, p.629-646, 2013.

Rezende, G.A.A.; Terrones, M.G.H.; Rezende, D.M.L.C. Estudo do potencial alelopatico do extrato metanolico de raiz e caule de Caryocar brasiliense Camb. (Pequi). Bioscience Journal, v.27, n.3, p.460-472, 2011.

Rickli, H.C.; Fortes, A.M.T.; Silva, P.S.S.; Pilatti, D.M.; Hutt, D.R. Efeito alelopático de extrato aquoso de folhas de Azadirachta indica A. Juss. em alface, soja, milho, feijão e picão-preto. Ciências Agrárias, v.32, p.473-484, 2011.

Rifai, N.M.; Miller, J.; Gadus, J.; Otepka, P.; Kosik, L. Comparison of infrared, flame and steam units for their use in plant protection. Research in Agricultural Engineering, v.2, n.49, p.65-73, 2003.

Ronchi, C.P.; Serrano, L.A.L.; Silva, A.A.; Guimarães, O.R. Weed management in tomato. Planta Daninha, v.28, n.1, p.215-228, 2010.

Santos, I.L.V.L.; Silva, C.R.C.; Santos, S.L.; Maia, M.M.D. Sorgoleone: benzoquinona lipídica de sorgo com efeitos alelopáticos na agricultura como herbicida. Arquivos do Instituto Biologico, v.79, n.1, p.135-144, 2012.

Scholberg, J.M.S.; Chase, C.A.; Linares, J.C.; Mcsorley, R.M.; Ferguson, J.J. Integrative approaches for weed management in organic citrus orchards. HortScience, v.4, p.949-954, 2006.

Sheikh, T.; Wheeler, T.A.; Dotray, P.A.; Zak, J. Biological Control of Woollyleaf Bursage (Ambrosia grayi) with Pseudomonas syringae pv. tagetis. Weed Technology, v.12, n.2, p. 375-381, 2001.

Silva, A.A.; Silva, C.S.W.; Souza, C.M.; Souza, B.A.; Fagundes, J.L.; Falleiro, R.M.; Sediyama, C.S. Aspectos fitossociológicos da comunidade de plantas daninhas na cultura do feijão sob diferentes sistemas de preparo do solo. Planta Daninha, v.23, n.1, p.17-24, 2005. 
Silva, J.; Fortes, A.M.T.; Gomes, F.M.; Pinto, T.T.; Bonamigo, T.; Boiago, N.P. Alelopatia de Camelina sativa Boiss. (Brassicaceae) sobre a germinação e desenvolvimento inicial de Bidens pilosa (L.) e Glycine $\max$ (L.) Merr. Revista Biotemas, v.24, n.4, p.17-24, 2011a.

Silva, M. C. C.; Braun, H.; Coelho, F. S. Manejo e controle de plantas daninhas na cultura da batata. Revista Brasileira de Agropecuária Sustentável, v.1, n.1, 2011 b.

Silva, M.R. Eficiência de flamejadores no controle de plantas daninhas. 2008. 127 f. Tese (Doutorado em Engenharia Agrícola) - Universidade Estadual de Campinas, Campinas, 2008.

Silva, M.R. Método físico para dessecação das ramas de batata. Batata Show: a Revista da Batata, v.1, n.18, p.52-55, 2007.

Silva, M.R.M.; Durigan, J.C. Períodos de interferência das plantas daninhas na cultura do arroz de terras altas. II - cultivar caiapó. Bragantia, v. 68 , n.2, p.373-379, 2009.

Souza, L.S.; Velini, E.D.; Martin, S.D.; Rosolem, C.A. Efeito alelopático de capim-braquiária (Brachiaria decumbens) sobre o crescimento inicial de sete espécies de plantas cultivadas. Planta Daninha, v.24, n.4, p.657-668, 2006.

Taylor, E.C.; Renner, K.A.; Christy, L.; Sprague, C.L. Organic weed management in field crops with a propane flamer and rotary hoe. Weed Technology, v.26, n.4, p.793-799, 2012.

Tehranchian, P.; Adair, R.J.; Lawrie, A.C. Potential for biological control of the weed Angled Onion (Allium triquetrum) by the fungus Stromatinia cepivora in Australia. Australasian Plant Pathology, v.4, n.43, p.381-392, 2014.

Trezzi, M.M.; Vidal, L.R.A. Potencial de utilização de cobertura vegetal de sorgo e milheto na supressão de plantas daninhas em condição de campo: II - Efeitos da cobertura morta. Planta Daninha, v.22, n.1, p.1-10, 2004.
Varejão, E.V.V.; Demuner, A.J.; Barbosa, L.C.A.; Barreto, R.W.; Vieira, B.S. Toxicidade de filtrados de cultura de Alternaria euphorbiicola em folhas de Euphorbia heterophylla. Planta Daninha, v.31, n.1, p.1-9, 2013.

Virbickaite, R.; Sirvydas, A.P.; Kerpauskas, P.; Vasinauskiene, R. The comparison of thermal and mechanical systems of weed control. Agronomy Research, v.4, n.special issue I, p.451-455, 2006.

Voll, E.; Franchini, J.C.; da Cruz, R.T.; Gazziero, D.L.P.; Brighenti, A.M.; Adegas, F.S. Chemical interactions of Brachiaria plantaginea with Commelina bengalensis and Acanthospermum hispidum in soybean cropping systems. Journal of Chemical Ecology, v.30, n.7, p.1467-1475, 2004.

Voll, E.; Voll, C.E.; Victória Filho, R. Allelopathic effects of aconitic acid on wild poinsettia (Euphorbia heterophylla) and morningglory (Ipomoea grandifolia). Journal of Environmental Science and Health, v.40, n.1, p.69-75, 2005.

White, S.S.; Renner, K.A.; Menalled, F.D.; Landis, D.A. Preferences of weed seed predators and effect on weed emergence. Weed Science, v.55, n.6, p.606-612, 2007.

Worthington, M.; Reberg-Horton, S.C. Breeding cereal crops for enhanced weed suppression: optimizing allelopathy and competitive ability. Journal of Chemical Ecology, v.39, n.2, p.213$231,2013$.

Yamauti, M.S.; Barroso, A.A.M.; Giancotti, P.R.F.; Squassoni, V.L.; Revolti, L.T.M.; Alves, P.L.C.A. Emergência de plantas daninhas em função da posição da semente e quantidade de palha de cana-de-açúcar. Scientia Agraria, v.12, n.2, p.75-80, 2011. 